\title{
Morphology, Phylogeny and Pathogenicity of Colletotrichum menglaense sp. nov., Isolated from Air in China
}

\author{
Min Qiao ${ }^{1}$, Jie Li ${ }^{1}$, Lin-lin Fang ${ }^{1}$, Jian-ying $\mathrm{Li}^{2}$ and Ze-fen $\mathrm{Yu}^{1, *}$ \\ 1 Laboratory for Conservation and Utilization of Bio-resources, Key Laboratory for Microbial Resources of the \\ Ministry of Education, Yunnan University, Kunming 650091, China; qiaoming@ynu.edu.cn (M.Q.); \\ lijie951021@163.com (J.L.); fllcsz@mail.ynu.edu.cn (L.-1.F.) \\ 2 Kunming Edible Fungi Institute of All China Federation of Supply and Marketing Cooperatives, \\ Kunming 650221, China; jianying0818@163.com \\ * Correspondence: zfyu@ynu.edu.cn
}

check for updates

Citation: Qiao, M.; Li, J.; Fang, L.-1.; Li, J.-y.; Yu, Z.-f. Morphology, Phylogeny and Pathogenicity of Colletotrichum menglaense sp. nov., Isolated from Air in China. Pathogens 2021, 10, 1243. https://doi.org/ $10.3390 /$ pathogens 10101243

Academic Editor: Sónia Gomes

Received: 3 August 2021

Accepted: 24 September 2021

Published: 26 September 2021

Publisher's Note: MDPI stays neutral with regard to jurisdictional claims in published maps and institutional affiliations.

Copyright: (c) 2021 by the authors. Licensee MDPI, Basel, Switzerland. This article is an open access article distributed under the terms and conditions of the Creative Commons Attribution (CC BY) license (https:/ / creativecommons.org/licenses/by/ $4.0 /)$.

\begin{abstract}
A new species, Colletotrichum menglaense, isolated from air in Mengla, Xishuangbanna, Yunnan Province, China, was characterized and described combining morphological characteristics and multigene phylogenetic analysis. Morphologically, it is characterized by oblong, sometimes slightly constricted, micro-guttulate conidia and simple obovoid to ellipsoidal appressoria. Phylogenetic analysis of the ITS, ACT, CHS, and GAPDH sequences showed that $C$. menglaense belongs to the C. gloeosporioides complex. The pathogenicity of $C$. menglaense on fruits of several crop plants, including strawberry, orange, grape, tomato, and blueberry, was tested and confirmed by the re-isolation of C. menglaense.
\end{abstract}

Keywords: airborne fungi; coelomycetes; Colletotrichum gloeosporioides complex; taxonomy; pathogenicity

\section{Introduction}

There are numerous bacteria and fungi in the near-surface atmosphere and upper troposphere, with millions of cells per cubic metre of air [1]. More than 40,000 species of fungi live in the air, mainly from soil, animals and plants, human activities, and excreta [2]. Fungi eject spores into the atmosphere by water jets or droplets, and become an important part of aerosols [3,4]. Hence, airborne fungi are closely related to air pollution, environmental quality, and human health.

Earlier investigations of microorganisms in air were connected with dust $[5,6]$ or aerosol particles [7-11] to detect the fungal distribution or characterisation. Other studies suggested that a considerable proportion of indoor airborne fungi were derived from outdoor fungi [12,13], and fungi had a great impact on human health [14-18]. With the advance of molecular approaches and the awareness of the importance of mycobiota diversity research, the number of studies about outdoor mycobiota is increasing. Many investigations recovered fungi from various places: the atmosphere in the urban environment of the USA [19], a rural area in India [20], at an altitude of 20,000 $\mathrm{m}$ in Earth's atmosphere [5], in southeastern Austria [16], and from the Himalayan region [21]. Most of these studies monitored remote, extreme, sparsely populated sites to learn the diversity, distribution, and seasonal variations of fungal species [22]. Several genera were often detected in air samples, Curviclavula G. Delgado et al. [23], Aspergillus P. Micheli, Penicillium Link, and Talaromyces C.R. Benj [13], and occasionally also species of Colletotrichum Corda [24,25].

Colletotrichum (Sexual morph: Glomerella) is a genus of the family Glomerellaceae, Glomerellales, Sordariomycetes, which was established with C. lineola Corda as the type species. Anthracnose, caused by the Colletotrichum species, is a major disease of plants, mainly fruit, worldwide. It causes significant yield losses and reduces the marketability of the fruit [26-29]. There is growing evidence showing that Colletotrichum spp. is ubiquitous and widespread. As one of the top ten plant pathogenic fungi in the world [30], many 
Colletotrichum species were isolated from diseased plants, e.g., C. miaoliense P.C. Chung \& H.Y. Wu and C. australianum W. Wang et al. were isolated from anthracnose symptoms on strawberry and citrus fruits [31,32]. In addition, Colletotrichum spp. were often reported as endophytes, including from healthy leaves of Bletilla ochracea [33]. Species of Colletotrichum are occasionally found as saprobes $[34,35]$. Some species were also isolated simultaneously as an endophyte, pathogen, and saprobe [36,37]. As for Colletotrichum spp. from air, an unidentified and a known species were reported. Colletotrichum sp. was isolated from the air of Dhaka, Bangladesh by Sultana [24]. Lal also trapped propagules of C. falcatum in air and confirmed that this species infected healthy plants [25].

When we investigated the fungi diversity of air samples in the town of Mengla, Xishuangbanna, a new species of Colletotrichum was identified based on morphological characteristics and DNA sequence data from four loci, and we named it $C$. menglaense. Its pathogenicity to several fruits was tested and confirmed by re-isolating the fungus.

\section{Results}

\subsection{Phylogenetic Analysis}

In the phylogenetic tree inferred from ITS, the strain is well clustered in the Colletotrichum gloeosporioides complex (not shown here). Therefore, we downloaded ITS, ACT, CHS, and GAPDH sequences in the $C$. gloeosporioides complex species. The dataset comprised 47 species, 67 isolates, and 1 outgroup taxa Monilochaetes infuscans (Table 1). A total of 1534 characters (ACT: 305, CHS: 300, GAPDH: 306, ITS: 623) were analysed by using Bayesian. The topologies of the tree were shown with the Bayesian posterior probability values for the analysed clades (Figure 1). In this tree, C. menglense is a sister clade to $C$. aeschynomenes B.S. Weir \& P.R. Johns and C. dianesei N.B. Lima, M.P.S. Câmara \& Michereff, and formed a single clade with high Bayesian inference posterior probability values (Figure 1). Therefore, we determined that our strain belonged to a novel species of Colletotrichum.

Table 1. Fungal strains and the GenBank accession numbers of their sequences used in molecular phylogenetic analyses in this study.

\begin{tabular}{|c|c|c|c|c|c|}
\hline \multirow{2}{*}{ Name of the Taxon } & \multirow{2}{*}{ Culture Collection } & \multicolumn{4}{|c|}{ GenBank Accessions Numbers } \\
\hline & & ACT & ITS & CHS & GAPDH \\
\hline C. aenigma & ICMP 18686 & JX009519 & JX010243 & JX009789 & JX009913 \\
\hline C. aeschynomenes & OBrC1 & KU239794 & KU239115 & KU239352 & KU239576 \\
\hline C. aeschynomenes & ICMP 17673 * & JX009483 & JX010176 & JX009799 & JX009930 \\
\hline C. alatae & CBS $304.67 *$ & JX009471 & JX010190 & JX009837 & JX009990 \\
\hline C. alienum & ICMP 18621 & JX009552 & JX010246 & JX009755 & JX009959 \\
\hline C. alienum & ICMP 12071 * & JX009572 & JX010251 & JX009882 & JX010028 \\
\hline C. aotearoa & ICMP 18532 & JX009544 & JX010220 & JX009764 & JX009906 \\
\hline C. asianum & MFLU 090232 & FJ903188 & FJ972605 & & FJ972571 \\
\hline C. asianum & MFLU 090234 & FJ907421 & FJ972615 & & FJ972573 \\
\hline C. asianum & MFLU 090233 & FJ907424 & FJ972612 & & FJ972576 \\
\hline C. boninense & CBS 128547 & JQ005507 & JQ005159 & JQ005333 & JQ005246 \\
\hline C. camelliae & ICMP 10643 * & JX009540 & JX010224 & JX009891 & JX009908 \\
\hline C. chengpingense & MFLUCC 150022 * & KР683093 & KP683152 & KP852449 & KP852469 \\
\hline C. clidemiae & ICMP 18658 * & JX009537 & JX010265 & JX009877 & JX009989 \\
\hline C. cliviae & CSSS1 & GU085861 & GU109479 & GU085865 & GU085867 \\
\hline C. communis & MTCC 11696 & KF451940 & KC790977 & KF451988 & KF452016 \\
\hline C. communis & MTCC 11695 & KF451941 & KC790980 & KF451989 & KF452017 \\
\hline C. conoides & CAUG34 & KP890146 & KP890170 & KP890158 & KP890164 \\
\hline C. conoides & CAUG17 * & KP890144 & KP890168 & KP890156 & KP890162 \\
\hline C. cordylinicola & ICMP 18579 * & HM470235 & JX010226 & JX009864 & JX009975 \\
\hline C. dianesei & CMM4078 & KC533745 & KC329775 & & KC517158 \\
\hline C. dianesei & CMM4081 & КС517304 & KC329790 & & KC517166 \\
\hline C. dianesei & CMM4077 & KC517295 & KC329773 & & KC517156 \\
\hline C. endophyticum & LC0324 & KF306258 & KC633854 & & KC832854 \\
\hline C. fructicola & ICMP 18120 & JX009436 & JX010182 & JX009844 & JX010041 \\
\hline
\end{tabular}


Table 1. Cont.

\begin{tabular}{|c|c|c|c|c|c|}
\hline \multirow{2}{*}{ Name of the Taxon } & \multirow{2}{*}{ Culture Collection } & \multicolumn{4}{|c|}{ GenBank Accessions Numbers } \\
\hline & & ACT & ITS & CHS & GAPDH \\
\hline C. fructicola & ICMP 18645 & JX009543 & JX010172 & JX009873 & JX009992 \\
\hline C. gloeosporioides & ICMP 17821 & JX009531 & JX010152 & JX009818 & JX010056 \\
\hline C. grevilleae & CBS $132879 *$ & KC296941 & KC297078 & KC296987 & KC297010 \\
\hline C. grossum & CAUG7* & KP890141 & KP890165 & KP890153 & KP890159 \\
\hline C. hebeiense & MFLUCC130726* & KF377532 & KF156863 & KF289008 & KF377495 \\
\hline C. helleniense & CPC 27108 & KY856022 & KY856449 & KY856189 & KY856273 \\
\hline C. henanense & $\mathrm{LF} 238 *$ & KM023257 & KJ955109 & & KJ954810 \\
\hline C. horii & NBRC $7478 *$ & JX009438 & GQ329690 & JX009752 & GQ329681 \\
\hline C. hymenocallidicola & MFLUCC 12-0531 & KT290260 & KT290264 & KT290262 & \\
\hline C. hymenocallidis & CAUG9 & KP145311 & KP145423 & KP145367 & KP145395 \\
\hline C. hystricis & CPC 28154 & KY856024 & KY856451 & KY856191 & KY856275 \\
\hline C. hystricis & CPC 28153 & KY856023 & KY856450 & KY856190 & KY856274 \\
\hline C. jasmini-sambac & HLTX-01 & & HM131512 & & HM131498 \\
\hline C. jasmini-sambac & LLTA-01 & HM131507 & HM131511 & & HM131497 \\
\hline C. jiangxiense & CGMCC3.17363 * & KJ954471 & KJ955201 & & KJ954902 \\
\hline C. cigarro & ICMP 18539 * & JX009523 & JX010230 & JX009800 & JX009966 \\
\hline C. menglaense & YMF1.04960 & MH023506 & MH023505 & MH023508 & MH023507 \\
\hline C. musae & ICMP 17817 & JX009432 & JX010142 & JX009815 & JX010015 \\
\hline C. musae & ICMP 19119 & JX009433 & JX010146 & JX009896 & JX010050 \\
\hline C. musae & ICMP 17923 & JX009587 & JX010143 & JX009841 & JX009929 \\
\hline C. nupharicola & ICMP 17938 & JX009486 & JX010189 & JX009834 & JX009936 \\
\hline C. nupharicola & ICMP 18187 & JX009437 & JX010187 & JX009835 & JX009972 \\
\hline C. nupharicola & ICMP 17940 & JX009582 & JX010188 & JX009836 & JX010031 \\
\hline C. proteae & CBS $132882 *$ & KC296940 & KC297079 & KC296986 & KC297009 \\
\hline C.psidii & ICMP 19120 * & JX009515 & JX010219 & JX009901 & JX009967 \\
\hline C. queenslandicum & ICMP $1778 *$ & JX009447 & JX010276 & JX009899 & JX009934 \\
\hline C. salsolae & CBS 130420 & JX009562 & JX010242 & JX009863 & JX009916 \\
\hline C. siamense & ICMP 18121 & JX009460 & JX010245 & JX009845 & JX009942 \\
\hline C. siamense & ICMP 18574 & JX009535 & JX010270 & JX009798 & JX010002 \\
\hline C. siamense & ICMP 12567 & JX009541 & $\mathrm{JX010250}$ & JX009761 & JX009940 \\
\hline C. syzygicola & MFLUCC100624* & KF157801 & KF242094 & & KF242156 \\
\hline C. theobromicola & ICMP 18649 & JX009444 & GU994360 & JX009869 & JX010006 \\
\hline C. $t i$ & ICMP $4832 *$ & JX009520 & JX010269 & JX009898 & JX009952 \\
\hline C. tropicale & ICMP 18651 & JX009570 & JX010277 & JX009868 & JX010014 \\
\hline C. tropicale & ICMP 18672 & JX009480 & JX010275 & JX009826 & JX010020 \\
\hline C. viniferum & GZAAS 5.08601 & JN412795 & JN412804 & & JN412798 \\
\hline C. viniferum & GZSSS 5.08608* & JN412793 & JN412802 & & JN412800 \\
\hline C. viniferum & CAUG27 & KP145328 & KP145440 & KP145384 & KP145412 \\
\hline C. wuxiense & CGMCC3.17894* & KU251672 & KU251591 & KU251939 & KU252045 \\
\hline C. xanthorrhoeae & ICMP 17903 & JX009478 & JX010261 & JX009823 & JX009927 \\
\hline C. yulongense & CFCC 50818 * & MH777394 & MH751507 & MH793605 & MK108986 \\
\hline Monilochaetes infuscans & CBS 869.96 & JQ005843 & JQ005780 & JQ005801 & JX546612 \\
\hline
\end{tabular}

Abbreviations of isolates and culture collections: MFLU: Mae Fah Luang University, Thailand; CMM: Culture Collection of Phythopathogenic Fung "Prof. Maria Menezes", Recife, Brazil; ICMP: International Collection of Micro-organisms from Plants, Landcare Research, New Zealand; MAFF: Ministry of Agriculture, Forestry and Fisheries, Tsukuba, Japan; MTCC: Microbial Type Culture Collection and Gene Bank, Chandigarh, India; MFLUCC: The Mae Fah Luang University Culture Collection; CPC: Culture collection of P.W. Crous, housed at the Westerdijk Institute; CBS: Westerdijk Fungal Biodiversity Institute, Utrecht, The Netherlands; YMF: formerly Key Laboratory of Industrial Microbiology and Fermentation Technology of Yunnan. * Ex-type strains. Sequences obtained in this study were shown in bold. 


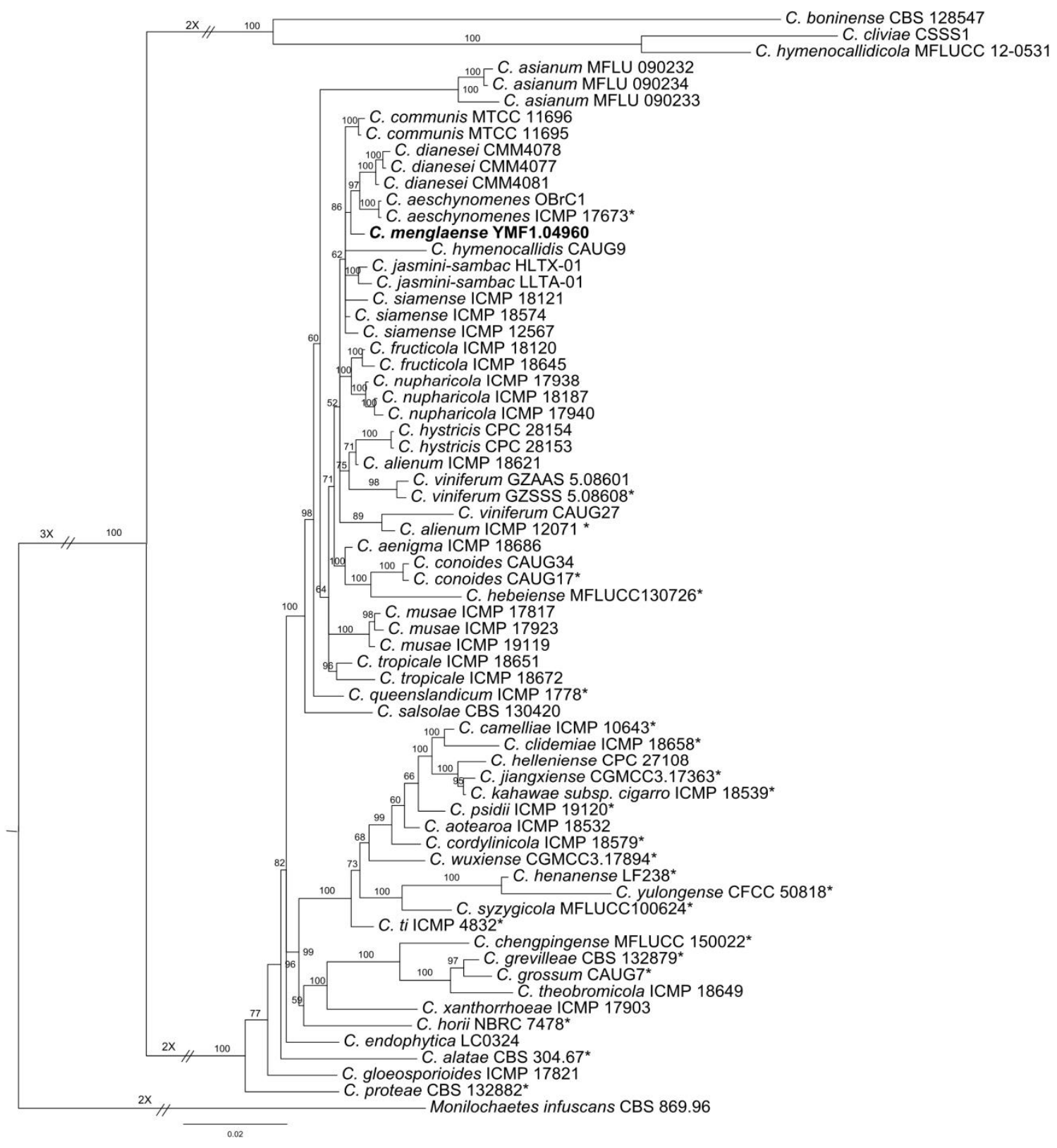

Figure 1. Phylogenetic tree based on Bayesian analysis of combined ITS, ACT, CHS, and GAPDH sequences. Monilochaetes infuscans was used as outgroup. Bayesian posterior probability values $\geq 0.85$ were shown at the nodes. The scale bar shows the expected changes per site. ${ }^{*}$ Ex-type strains. Newly described taxa were shown in boldface.

\subsection{Pathogenicity Test}

After 7 days, five kinds of fruit inoculated with conidia suspension developed pale white hyphae around the wounds, and typical dark brown anthracnose lesions appeared on the strawberries, but no symptoms developed on the controls. Strawberry and tomato were the most susceptible, with disease scores from 7 to 9 (Table 2). Then, after 14 days, there were obvious anthracnose lesions around the wounds of the strawberry, orange, and tomato fruits. In fact, all of the fruits were susceptible to YMF 1.04960. The results showed that C. menglaense YMF 1.04960 is not host-specific (Figure 2). 
Table 2. Disease Score (DS) on a 0-9 scale of different fruits for C. menglaense inoculated by wounding or non-wounding methods.

\begin{tabular}{cccccc}
\hline \multirow{2}{*}{ Number of Days } & \multicolumn{5}{c}{ Fruit } \\
\cline { 2 - 6 } & Strawberry & Orange & Grape & Tomato & Blueberry \\
\hline 7 & 7 & 3 & 1 & 9 & 3 \\
14 & 9 & 9 & 3 & 9 & 9 \\
\hline
\end{tabular}
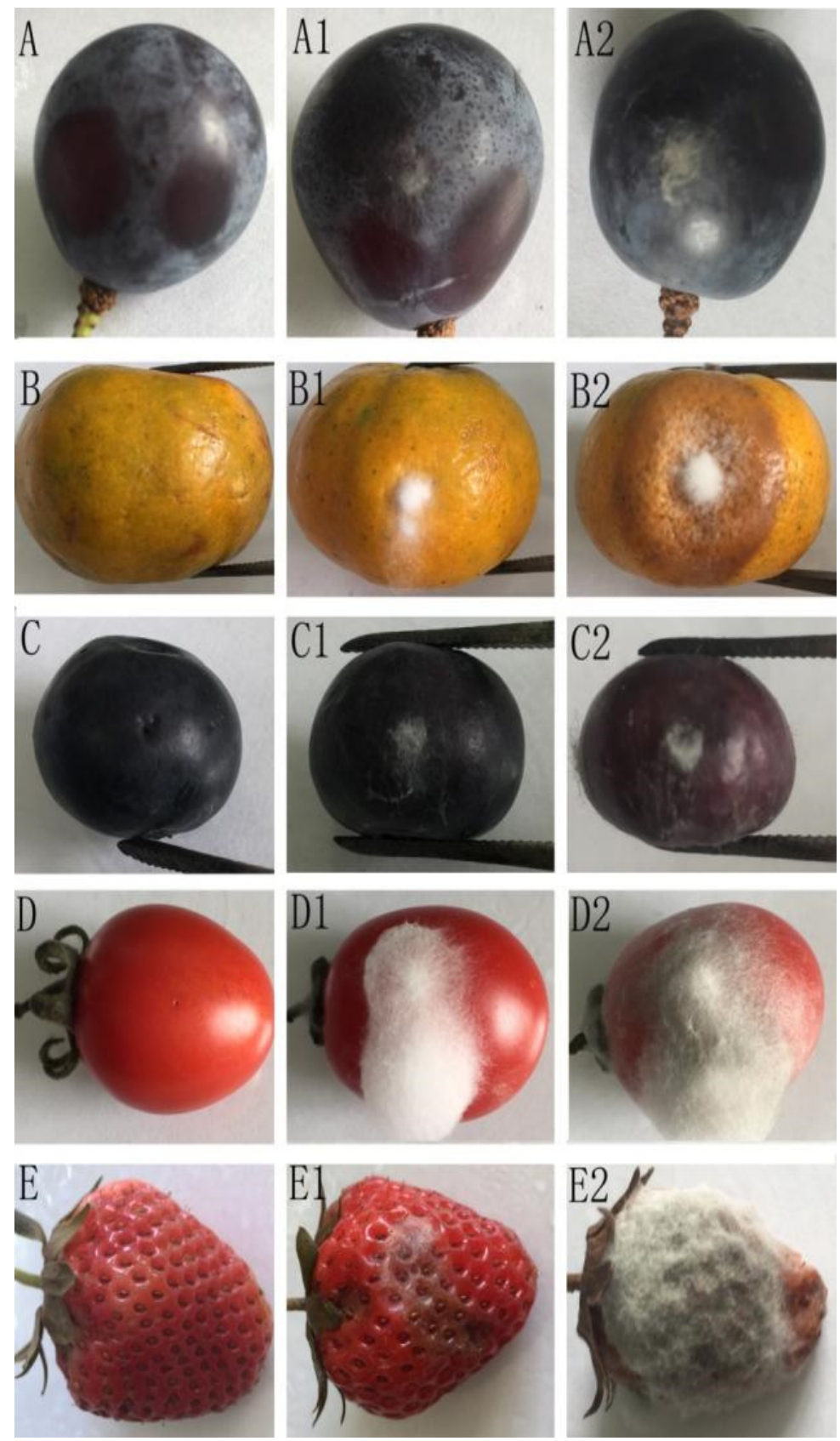

Figure 2. Pathogenicity test results of $C$. menglaense. (A-E). Control fruit. (A1-E1). Symptoms on fruits $7 \mathrm{~d}$ after inoculation. (A2-E2). Symptoms on fruits $14 \mathrm{~d}$ after inoculation.

The conidia isolated from the infected fruits are the same as those of YMF 1.04960 (Figure 3F), and the ITS sequence is also the same as YMF 1.04960. So, the pathogenicity was confirmed. 

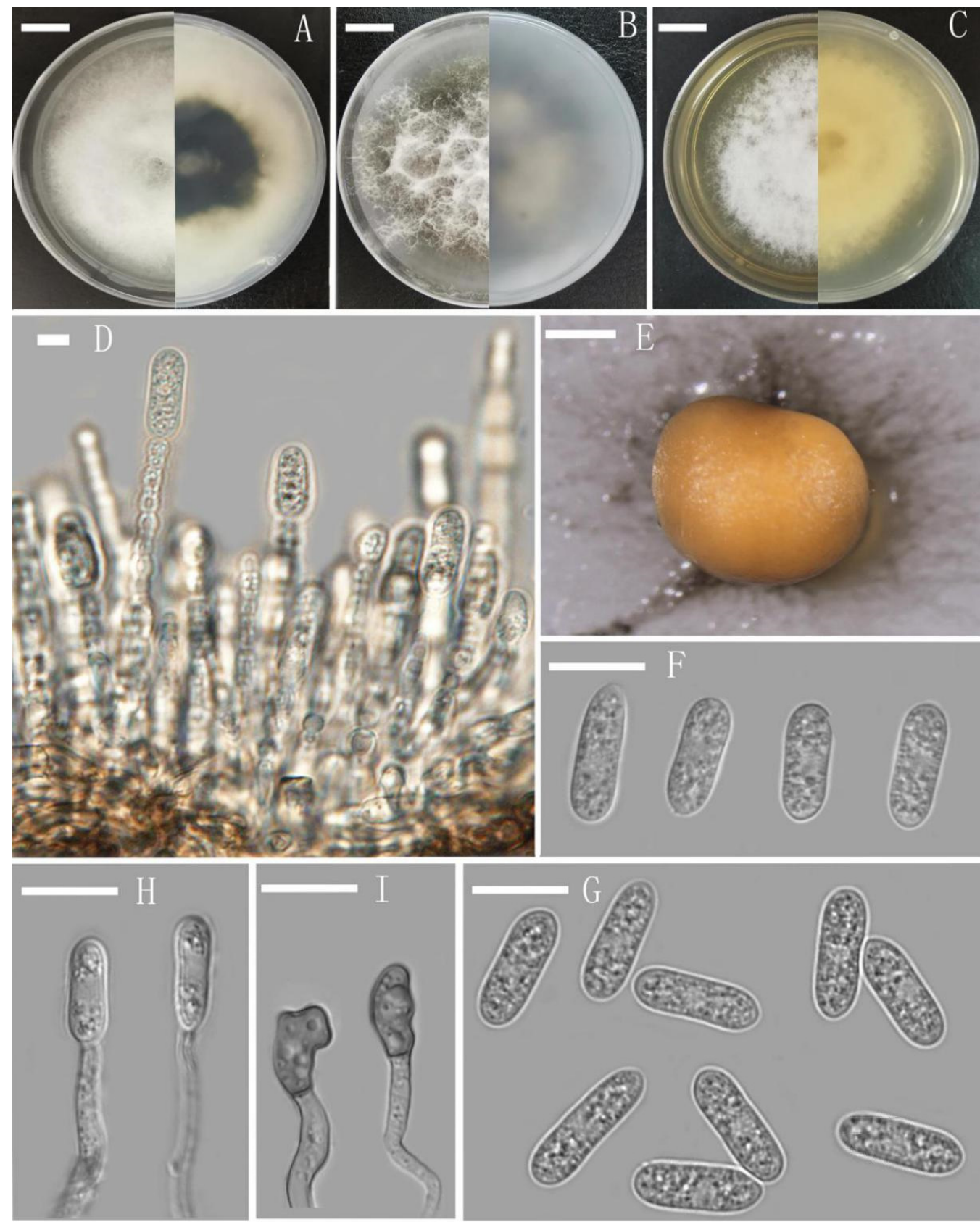

Figure 3. Colletotrichum menglaense (YMF1.04960). (A): Culture grown on PDA above and below (B): Culture grown on CMA above and below. (C): Culture grown on MEA above and below. $(\mathbf{D}, \mathbf{H})$ : Conidiophores and conidia. (E): Conidioma on CMA. (F): Conidia from infected fruits. (I): Appressoria. (G): Conidia. Scale bars: $(\mathbf{A}-\mathbf{C})=1.37 \mathrm{~cm}$. (D) $=0.6 \mu \mathrm{m}$. $(\mathbf{E})=500 \mu \mathrm{m} .(\mathbf{F}, \mathrm{G})=10 \mu \mathrm{m}$.

\subsection{Taxonomy}

Colletotrichum menglaense M. Qiao \& Z. F. Yu, sp. nov. -MycoBank: MB 839092; Figure 3.

Etymology: Latin, menglaense, referred to Mengla, the locality of the isolation in Yunnan Province.

Type: CHINA, Xishuangbanna Dai Autonomous Prefecture, Tropical Forest of Xishuangbanna Tropical Botanical Garden Chinese Academy of Sciences, $21^{\circ} 41^{\prime} \mathrm{N}, 101^{\circ} 25^{\prime} \mathrm{E}$, ca $570 \mathrm{~m}$, collected from the air, Jul 2016, Zefen Yu (holotype: YMF1.04960, ex-holotype: CGMCC 3.18958).

Description: Colonies growing on CMA with entire margin, 28-32 mm diameter in $4 \mathrm{~d}$ at $28^{\circ} \mathrm{C}$; aerial mycelia medium grey to pale buff in centre, light grey to greyish white 
in the margin, entirely covered with floccose to dense. Reverse dark white to grey with white margin. Conidiomata acervular, with orange conidial masses. No setae observed. Conidiophores cylindrical, unbranched or branched, straight or flexuous, 0-1-septate, hyaline, branched, 14.9-59.7 $\mu \mathrm{m} \times 1.4-3.3 \mu \mathrm{m}$. Conidiogenous cells monophialidic, subulate, integrated, determinate, terminal, hyaline. Conidia acrogenous, oblong, sometimes slightly constricted at the middle, micro-guttulate, hyaline, unicellular, smooth-walled, 12.2-17.1 $\mu \mathrm{m} \times 4.2-6.4 \mu \mathrm{m}(\mathrm{av} .=14.4 \mu \mathrm{m} \times 5.1 \mu \mathrm{m}, n=30)$. Appressoria simple, brown to dark brown, aseptate, mostly ellipsoidal to broadly obovoid, entire or irregular, somewhat crenate to lobed at margin, 6.7-20.0 $\mu \mathrm{m} \times 4.8-11.0 \mu \mathrm{m}, \mathrm{L} / \mathrm{W}$ ratio $=2.7$.

Notes: C. menglaense can be distinguished from phylogenetically closely related C. aeschynomenes and $C$. dianesei by the dimensions of conidia. The conidia of $C$. menglaense are shorter $(12.2-17.1 \mu \mathrm{m} \times 4.2-6.4 \mu \mathrm{m}$, mean $=14.4 \mu \mathrm{m} \times 5.1 \mu \mathrm{m}, n=30)$ than those of C. aeschynomenes (14-)17-18.5 (-20) $\mu \mathrm{m} \times 4(-5) \mu \mathrm{m}($ mean $=17.6 \mu \mathrm{m} \times 4.1 \mu \mathrm{m}$, $n=30)$ [38] and longer and narrower than those of $C$. dianesei $(10.5-14.5 \mu \mathrm{m} \times 4-5.5 \mu \mathrm{m}$, mean $=12.0 \mu \mathrm{m} \times 4.5 \mu \mathrm{m}, n=30)[39]$.

\section{Materials and Methods}

\subsection{Sample Collection and Morphological Characterisation}

Samples were collected from the Tropical Forest of Xishuangbanna Tropical Botanical Garden, Chinese Academy of Sciences $\left(101^{\circ} 25^{\prime} \mathrm{E}, 21^{\circ} 41^{\prime} \mathrm{N}\right.$, altitude $570 \mathrm{~m}$ ) in Mengla, Yunnan Province, China in July 2015. For each sample, we used a surface air system (SAS) Super ISO 180 (VWR European Cat.No.710-0870, San Giusto, Italy) that takes five minutes to capture 1,000 L of air. A $90 \mathrm{~mm}$ Petri dish containing RBA (5 g peptone, $10 \mathrm{~g}$ dextrose, $1 \mathrm{~g}$ potassium dihydrogen phosphate, $0.5 \mathrm{~g}$ magnesium sulfate, $15 \mathrm{~g}$ agar, $0.033 \mathrm{~g}$ rose bengal, $0.1 \mathrm{~g}$ chloramphenicol, $1000 \mathrm{~mL}$ distilled water) was put on the sampler for a few seconds to collect air. The Petri dishes were immediately sealed after air collection and brought back to the laboratory. Petri dishes were incubated in the continuous light at outdoor ambient temperature (mean $25^{\circ} \mathrm{C}$ ) and examined periodically. When a few mycelium appeared, it was picked up and transferred to PDA (200 g potato, $20 \mathrm{~g}$ glucose, $18 \mathrm{~g}$ agar, $40 \mathrm{mg}$ streptomycin, $30 \mathrm{mg}$ ampicillin, $1000 \mathrm{~mL}$ distilled water) dishes for incubation at $25^{\circ} \mathrm{C}$. The pure cultures were further incubated on CMA (20 g cornmeal, $18 \mathrm{~g}$ agar, $40 \mathrm{mg}$ streptomycin, $30 \mathrm{mg}$ ampicillin, $1000 \mathrm{~mL}$ distilled water) dishes to induce sporulation. Colony morphology and microscopic characteristics were examined, measured, and photographed after incubation for 7 days by using the aid of a BX51 microscope.

The pure culture was deposited in the Herbarium of the Laboratory for Conservation and Utilization of Bio-resources, Yunnan University, Kunming, Yunnan, China (YMF, formerly Key Laboratory of Industrial Microbiology) and the China General Microbiological Culture Collection Centre (CGMCC).

\subsection{DNA Extraction, PCR Amplification, and Sequencing}

Detailed protocols for Genomic DNA extraction are described previously $[40,41]$. The relative quantity of total genomic DNA was observed on a $1 \%$ TAE agarose gel stained with ethidium bromide. The following loci were amplified with the indicated primers: the internal transcribed spacer (ITS) region and actin gene (ACT) with primers ITS4/ITS5 [42,43]; ACT512F/ACT783R [40], respectively. The thermo-cycling parameters were used: initial denaturation at $95^{\circ} \mathrm{C}$ for $3 \mathrm{~min}$, followed by 34 cycles of $95^{\circ} \mathrm{C}$ for $1 \mathrm{~min}$, $52{ }^{\circ} \mathrm{C}$ for $30 \mathrm{~s}, 72{ }^{\circ} \mathrm{C}$ for $1 \mathrm{~min}$, with a final extension step of $72{ }^{\circ} \mathrm{C}$ for $10 \mathrm{~min}$. Chitin synthase 1 (CHS-1) were amplified with CHS-79F/CHS-354R [44]. The cycling parameters consisted of $94{ }^{\circ} \mathrm{C}$ for $5 \mathrm{~min}$, followed by 35 cycles at $94{ }^{\circ} \mathrm{C}$ for $30 \mathrm{~s}, 56^{\circ} \mathrm{C}$ for $30 \mathrm{~s}, 72{ }^{\circ} \mathrm{C}$ for $90 \mathrm{~s}$, and a final extension step of $72^{\circ} \mathrm{C}$ for $7 \mathrm{~min}$. Partial sequences of the glyceraldehyde -3-phosphate dehydrogenase (GAPDH) were amplified with primers GDF1/GDR1 [45]. The cycling parameters consisted of a denaturation step at $94{ }^{\circ} \mathrm{C}$ for $4 \mathrm{~min}$, followed by 34 cycles at $94{ }^{\circ} \mathrm{C}$ for $45 \mathrm{~s}, 60{ }^{\circ} \mathrm{C}$ for $45 \mathrm{~s}, 72{ }^{\circ} \mathrm{C}$ for $1 \mathrm{~min}$, and a final cycle at $72{ }^{\circ} \mathrm{C}$ for 
$10 \mathrm{~min}$. Amplification was performed in a total of $25 \mu \mathrm{L}$ reaction volume, which contained $1.0 \mu \mathrm{L}$ DNA template, $1.0 \mu \mathrm{L}$ of each forward and reverses primer, $12.5 \mu \mathrm{L} 2 \times$ Master Mix (Tiangen Biotech, Beijing, China), and $9.5 \mu \mathrm{L} \mathrm{dd} \mathrm{H}_{2} \mathrm{O}$. The sequencing reactions were carried out by TsingKe Biological Technology, Kunming, China using the same primers as for amplification. The new sequences were submitted to the GenBank database at the National Center for Biotechnology Information (NCBI), and the accession numbers are listed in Table 1.

\subsection{Phylogenetic Analysis}

The obtained ITS sequences were compared with those in GenBank using BLAST searches to determine the primary phylogenetic placement of the fungus. The results indicated that our strain belongs to Colletotrichum. Neighbour-joining analysis of ITS sequence was used to determine further phylogenetic placement. Then, we retrieved ITS, ACT, GAPDH, and CHS sequences of representative species and additional species belonging to this complex species. All sequences used in this study are listed in Table 1 and were aligned through ClustalX 1.83(Institut de Genetique et de Biologie Moleculaire et Cellulaire (CNRS/INSERM/ULP), Illkirch-Graffenstaden, France) [46]. The resulting alignments were subsequently manually adjusted and linked by BioEdit version v. 7.0(Borland, Austin, TX, United States) [47]. To ensure that all sequences are of the same length, the missing base was replaced with "?". Then, the combined alignment was converted to a NEXUS file using the program mega7(Mega Limited, Auckland, New Zealand) [48]. Phylogenetic analyses were performed for Bayesian inference (BI) analysis using MrBayes v.3.2.2 (Department of Biodiversity Informatics, Swedish Museum of Natural History, Stockholm, Sweden) [49].

For BI analysis, the best nucleotide substitution model for each locus was determined using Mrmodeltest v. 2.3 (Department of Systematic Zoology, Evolutionary Biology Centre, Uppsala University, Uppsala, Sweden) [50]. The analyses of four MCMC chains were run from random trees for 1,000,000 generations, and trees were sampled every 100 generations, resulting in 20,000 total trees. The first $25 \%$ of the trees were discarded as the burn-in phase of each analysis, and the remaining trees were used to calculate posterior probabilities. Sequences derived in this study were deposited in GenBank (Table 1), and the concatenated alignments were deposited in TreeBASE with http://purl.org/phylo/treebase/phylows/ study/TB2:S27941, and the descriptions and nomenclature in MycoBank (www.mycobank.org).

\subsection{Pathogenicity Assay and Confirmation}

In order to test the pathogenicity of the new species, detached fruits inoculations were conducted. Healthy Fragaria ananassa Duch. (strawberry), Citrus tachibana (Makino) Tanaka (orange), Vitis vinifera L. (grape), Lycopersicon esculentum Mill. (tomato), and Vaccinium uliginosum Linn. (blueberry) were used for the pathogenicity test. All fruits were immersed in 70\% ethanol for $3 \mathrm{~min}$ and $1 \%$ sodium hypochlorite for $3 \mathrm{~min}$, then rinsed three times in sterile distilled water and air dried in the laminar flow cabinet.

Prior to the inoculation, holotype strain YMF 1.04960 of new species was cultivated on CMA for 7 days at $28^{\circ} \mathrm{C}$, adding $0.4 \mathrm{~g}$ yeast extract per $100 \mathrm{~mL}$ to induce sporulation. After incubation, conidia were harvested by adding $10 \mathrm{~mL}$ sterile water to each culture followed by scraping the surface with a sterile brush. The resulting conidia suspensions were filtered through sterile six layers of filter paper. Then, conidia were diluted to $10^{6} / \mathrm{mL}$ using sterile water (concentration was adjusted by using a haemocytometer). Fruit were wounded with a sterilised insect needle and inoculated with $10 \mu \mathrm{L}$ conidium suspension. Control fruits were inoculated with sterilised water. Five replications were set. The inoculated fruits with the controls were put into plastic containers, covered with plastic wrap to maintain humidity, sealed and stored in a constant temperature incubator, and examined periodically.

Seven days and 14 days after inoculation, the virulence was evaluated as described by Montri et al. [51]. In particular, 0 (highly resistant), no infection; 1 (resistant), 1-2\% of the fruit with a necrotic lesion or a larger water soaked lesion surrounding the infection site; 3 (moderately resistant), >2 to $5 \%$ of the fruit with a necrotic lesion, possibly acervuli, 
may be present, or a watery lesion covering up to $5 \%$ of the fruit surface; 5 (susceptible), $>5$ to $10 \%$ of the fruit showing a necrotic lesion, possibly acervuli, or a water-soaked lesion covering up to $25 \%$ of the fruit surface; 7 (very susceptible), $>10$ to $25 \%$ of the fruit covered with a necrotic lesion with acervuli; and 9 (highly susceptible), $>25 \%$ of the fruit showing necrosis, lesion often encircling the fruit, abundant acervuli. Symptomatic fruits were surface-sterilised as described above. The symptomatic tissue segments were cut with a sterilised scalpel about $5 \mathrm{~mm} \times 5 \mathrm{~mm} \times 5 \mathrm{~mm}$ and then placed on the PDA to re-isolate the fungus. The identity of obtained isolates was confirmed on the basis of morphological characteristics and ITS sequence.

\section{Discussion}

ITS has been proposed as the official fungal barcoding marker [52], but phylogenetic analysis using only ITS sequences could not confidently resolve the phylogenetic placement of some species within Colletotrichum. In this study, phylogenetic analysis based on ITS showed that C. menglaense could not be distinguished from C. queenslandicum, C. salasolae, and C. siamense, but the results showed that $C$. menglaense is well clustered in the C. gloeosporioides species complex, so we further used multi-locus phylogeny to distinguish closely related species. Combining sequences of ITS, ACT, CHS, and GAPDH, the phylogenetic position of $C$. menglaense was determined. In the phylogenetic tree, the species relationships were well defined, with all of the major clades supported by high Bayesian inference posterior probabilities (Figure 1). C. menglaense grouped together with C. aeschynomenes and C. dianesei, and the ITS similarity between C. menglaense and C. aeschynomenes (KU239115) is $99.08 \%$, while, between C. menglaense and C. dianesei (KC329775), it is $99.47 \%$. Morphologically, C. menglaense obviously differs from $C$. aeschynomenes and $C$. dianesei in the shape and size of the conidia.

The pathogenicity test showed that $C$. menglaense may be a potential pathogen to fruit. Among all of the test fruits, C. menglaense was very aggressive on strawberries, while it was less aggressive on blueberries and grapes. This is in agreement with Xavier et al., who reported that the C. gloeosporioides species complex was more aggressive to strawberry than other Colletotrichum species complex organisms [53]. The degree of fruit infection may be related to fruit condition, humidity, temperature, inoculum concentration, and inoculation method [54], so, among fruits tested here, strawberry with softer tissue showed the highest disease scores of 5 to 9. Several fruits inoculated with C. menglaense presented different degrees of anthracnose, indicating that C. menglaense was non-host specific. In fact, many Colletotrichum species present on a wide range of host plants [27,55]. For example, C. karstiiwas was reported from diseased black plum (Diospyros australis), strawberry (Fragaria xananassa), and banana (Musa nana Lour). C. gloeosporioides species complex organisms were also frequently isolated from a variety of hosts, including kumquat, finger lime, grapefruit, lemon, lime, mandarin, orange, and Persian lime $[37,56]$.

Previously, it was reported that Cladosporium was the most frequent fungus in the air; the next were Fusarium, Alternaria, and Epicoccum [57]. Some leaf surface fungi are major contributors to air spores through the action of wind or rain spatter, and the canopy is closer to the leaves of the plant, so there are more fungal spores in the air below the canopy [58]. Similar to previous reports, the air samples that we obtained were collected in the lower part of the canopy. Besides, some airborne spores have been reported to be pathogenic fungi. Alternaria alternata airborne spores might be sufficient to cause human spore-related asthma symptoms to people even with only a limited concentration [59]. Here, $C$. menglaense is an airborne fungus that has certain pathogenicity to plants. Previous studies also showed that Colletotrichum spp. from air were pathogenic fungi to plants [25]. Due to limited study, we do not know how many pathogenic fungi are present in the air and how they contribute to the spread of plant diseases. In this respect, the present article provides new information. 
Author Contributions: Z.-f.Y. conceived and designed the study. M.Q. and J.L. wrote the manuscript. J.-y.L. and L.-1.F. conducted the experiments. Z.-f.Y. and J.L. revised the manuscript. All authors have read and agreed to the published version of the manuscript.

Funding: This work was jointly financed by National Natural Science Foundation Program of PR China $(31760012,31970013)$.

Institutional Review Board Statement: Not applicable.

Informed Consent Statement: Not applicable.

Data Availability Statement: All sequences have been deposited in GenBank at the accession numbers given in the text. The GenBank accession numbers of Colletotrichum menglaense: ITS MH023505; ACT MH023506; GAPDH MH023507; CHS MH023508.

Acknowledgments: We are grateful to reviewers for critically reviewing the manuscript and for providing helpful suggestions to improve this paper. We are also grateful for the support of Yunnan University Research and Innovation Fund for Postgraduates (2020268).

Conflicts of Interest: The authors declare that there are no conflict of interest.

\begin{abstract}
Abbreviations
RBA: Rose Bengal Agar; PDA, potato dextrose agar; CMA, corn meal agar; ITS, internal transcribed spacer; ACT, actin gene; CHS-1, chitin synthase 1; GAPDH, the glyceraldehyde-3-phosphate dehydrogenase.
\end{abstract}

\title{
References
}

1. Bowers, R.M.; Clements, N.; Emerson, J.B.; Wiedinmyer, C.; Hannigan, M.P.; Fierer, N. Seasonal variability in bacterial and fungal diversity of the near-surface atmosphere. Env. Sci. Technol. 2013, 47, 12097. [CrossRef]

2. Li, D.W.; Kendrick, B. Functional relationships between airborne fungal sporesand enviromental factors in Kitchener-Waterloo, Ontario, as detected by Canonical correspondence analysis. Grana 1994, 33, 166-176. [CrossRef]

3. Elbert, W.; Taylor, P.E.; Andreae, M.O.; Pöschl, U. Contribution of fungi to primary aerosols in the atmosphere: Wet and dry discharged spores, carbohydrates, and inorganic ions. Atmos. Chem. Phys. 2007, 7, 4569-4588. [CrossRef]

4. Heald, C.L.; Spracklen, D.V. Atmospheric budget of primary biological aerosol particles from fungal spores. Geophys. Res. Lett. 2009, 36, 1-5. [CrossRef]

5. Griffin, D.W. Terrestrial Microorganisms at an Altitude of 20,000 m in Earth's Atmosphere. Aerobiologia 2004, 20, 135-140. [CrossRef]

6. Anthony, J.P.; Markus, D.P.; Sonia, M.K.; Colette, L.H.; Scot, T.M.; Paulo, A.; Rebecca, M.G.; Adam, G.W.; Ulrich, P. Relative roles of biogenic emissions and Saharan dust as ice nuclei in the Amazon basin. Nat. Geosci. 2009, 2, 402-405.

7. Atin, A.; Tiina, R.; Sergey, A.G.; Dainius, M.; Grace, L. Correlation of ambient inhalable bioaerosols with particulate matter and ozone: A two-year study. Environ. Pollut. 2006, 140, 16-28.

8. Després, V.R.; Nowoisky, J.F.; Klose, M.; Conrad, R.; Andreae, M.O.; Pöschl, U. Characterization of primary biogenic aerosol particles in urban, rural, and high-alpine air by DNA sequence and restriction fragment analysis of ribosomal RNA genes. Biogeosciences 2007, 4, 1127-1141. [CrossRef]

9. Heidi, B.; Elisabeth, S.; Gert, W.; Anna, B.; Regina, H.; Iain, L.M.; Hans, P. Significant contributions of fungal spores to the organic carbon and to the aerosol mass balance of the urban atmospheric aerosol. Atmos. Environ. 2008, 42, 5542-5549.

10. Dannemiller, K.C.; Lang-Yona, N.; Yamamoto, N.; Rudich, Y.; Peccia, J. Combining real-time PCR and next-generation DNA sequencing to provide quantitative comparisons of fungal aerosol populations. Atmos. Environ. 2014, 84, 113-121. [CrossRef]

11. Liang, L.; Engling, G.; Du, Z.; Duan, F.; Cheng, Y.; Liu, X.; He, K. Contribution of fungal spores to organic carbon in ambient aerosols in Beijing, China. Atmos. Pollut. Res. 2017, 8, 351-358. [CrossRef]

12. Cetinkaya, Z.; Fidan, F.; Unlu, M.; Hasenekoglu, I.; Demirel, R. Assessment of indoor air fungi in Western-Anatolia, Turkey. Asian Pac. J. Allegy 2005, 23, 87.

13. Visagie, C.M.; Hirooka, Y.; Tanney, J.B.; Whitfield, E.; Mwange, K.; Meijer, M.; Amend, A.S.; Seifert, K.A.; Samson, R.A. Aspergillus, Penicillium and Talaromyces isolated from house dust samples collected around the world. Stud. Mycol. 2014, 78, 63-139. [CrossRef]

14. Rafał, L.G.; Tiina, R.; Sergey, A.G.; Klaus, W. Source strength of fungal spore aerosolization from moldy building material. Atmos. Environ. 2001, 35, 4853-4862.

15. Górny, R.L.; Reponen, T.; Willeke, K.; Schmechel, D.; Robine, E.; Boissier, M.; Grinshpun, S.A. Fungal fragments as indoor air biocontaminants. Appl. Environ. Microb. 2002, 68, 3522-3531. [CrossRef]

16. Haas, D.; Habib, J.; Luxner, J.; Galler, H.; Zarfel, G.; Schlacher, R.; Friedl, H.; Reinthaler, F.F. Comparison of background levels of culturable fungal spore concentrations in indoor and outdoor air in southeastern Austria. Atmos. Environ. 2014, 98, 640-647. [CrossRef] 
17. Lee, T.; Grinshpun, S.A.; Martuzevicius, D.; Adhikari, A.; Crawford, C.M.; Reponen, T. Culturability and concentration of indoor and outdoor airborne fungi in six single-family homes. Atmos. Environ. 2006, 40, 2902-2910. [CrossRef] [PubMed]

18. Nasir, Z.A.; Colbeck, I.; Sultan, S.; Ahmed, S. Bioaerosols in residential micro-environments in low income countries: A case study from Pakistan. Environ. Pollut. 2012, 168, 15-22. [CrossRef] [PubMed]

19. Levetin, E. Studies on airborne basidiospores. Aerobiologia 1990, 6, 177-180. [CrossRef]

20. Adhikari, A.; Sen, M.M.; Gupta-Bhattacharya, S.; Chanda, S. Airborne viable, non-viable, and allergenic fungi in a rural agricultural area of India: A 2-year study at five outdoor sampling stations. Sci. Total. Environ. 2004, 326, 123-141. [CrossRef] [PubMed]

21. Kumar, A.; Attri, A.K. Characterization of fungal spores in ambient particulate matter: A study from the Himalayan region. Atmos. Environ. 2016, 142, 182-193. [CrossRef]

22. Froehlich-Nowoisky, J.; Pickersgill, D.A.; Despres, V.R.; Poeschl, U. High diversity of fungi in air particulate matter. Proc. Natl. Acad. Sci. USA 2009, 106, 12814-12819. [CrossRef]

23. Delgado, G.; Miller, A.N.; Fernández, F.A. Curviclavula, a new genus of anamorphic Helotiales (Leotiomycetes) isolated from air. Mycol. Prog. 2015, 14, 3. [CrossRef]

24. Sultana, T. Aeromycoflora of Dhaka city, Bangladesh. Master's Thesis, University of Dhaka, Dhaka, Bangladesh, October 2016.

25. Singh, R.P.; Lal, S. Air borne propagules of Colletotrichum falcatum and their role in the epidemiology of sugarcane red rot. Indian Phytopathol. 1996, 49, 89-91.

26. Meneses, P.R.; Dorneles, K.R.; Bellé, C.; Moreira-Nuñez, V.L.; Gaviria-Hernández, V.; de Farias, C.R.J. Detection of Colletotrichum boninense causing leaf anthracnose on Alcantarea imperialis in Brazil. Plant Dis. 2019, 103, 2125. [CrossRef]

27. Cacciola, S.O.; Gilardi, G.; Faedda, R.; Schena, L.; Pane, A.; Garibaldi, A.; Gullino, M.L. Characterization of Colletotrichum ocimi population associated with black spot of sweet basil (Ocimum basilicum) in Northern Italy. Plants 2020, 9, 654. [CrossRef]

28. Dowling, M.; Peres, N.; Villani, S.; Schnabel, G. Managing Colletotrichum on fruit crops: A “complex" challenge. Plant Dis. 2020, 104, 2301-2316. [CrossRef] [PubMed]

29. Peres, N.A.; Timmer, L.W.; Adaskaveg, J.E.; Correll, J.C. Lifestyles of Colletotrichum acutatum. Plant Dis. 2005, 89, 784-796. [CrossRef]

30. Kan, R.D.J. The Top 10 fungal pathogens in molecular plant pathology. Mol. Plant. Pathol. 2012, 13, 414-430.

31. Chung, P.C.; Wu, H.Y.; Wang, Y.W.; Hiran, A.A.; Hsien-Pin, H.; Ting-Hsuan, H.; Shean-Shong, T.; Chung, C.L. Diversity and pathogenicity of Colletotrichum species causing strawberry anthracnose in Taiwan and description of a new species, Colletotrichum miaoliense sp. nov. Sci. Rep. 2020, 10, 14664. [CrossRef]

32. Wang, W.; de Silva, D.D.; Moslemi, A.; Edwards, J.; Ades, P.K.; Crous, P.W.; Taylor, P.W.J. Colletotrichum species causing anthracnose of citrus in Australia. J. Fungi 2021, 7, 47. [CrossRef] [PubMed]

33. Tao, G.; Liu, Z.Y.; Liu, F.; Gao, Y.H.; Cai, L. Endophytic Colletotrichum species from Bletilla ochracea (Orchidaceae), with descriptions of seven new species. Fungal Divers. 2013, 61, 139-164. [CrossRef]

34. Osono, T.; Ishii, Y.; Takeda, H.; Khamyong, S.; And, S. Fungal succession and lignin decomposition on Shorea obtusa leaves in a tropical seasonal forest in northern Thailand. Fungal Divers. 2009, 36, 101-119.

35. Thongkantha, S.; Lumyong, S.; McKenzie, E.H.C.; Hyde, K.D. Fungal saprobes and pathogens occurring on tissues of Dracaena lourieri and Pandanus spp. in Thailand. Fungal Divers. 2008, 30, 149-169.

36. Yang, Y.L.; Liu, Z.Y.; Cai, L.; Hyde, K.D.; Yu, Z.N.; McKenzie, E.H.C. Colletotrichum athnracnose of Amaryllidaceae. Fungal Divers. 2009, 39, 123-146.

37. Riolo, M.; Aloi, F.; Pane, A.; Cara, M.; Cacciola, S.O. Twig and shoot dieback of citrus, a new disease caused by Colletotrichum species. Cells 2021, 10, 449. [CrossRef]

38. Weir, B.S.; Johnston, P.R.; Damm, U. The Colletotrichum gloeosporioides species complex. Stud. Mycol. 2012, 73, 115-180. [CrossRef]

39. Lima, N.B.; Batista, M.V.D.A.; De Morais, M.A.; Barbosa, M.A.G.; Michereff, S.J.; Hyde, K.D.; Câmara, M.P.S. Colletotrichum species are responsible for mango anthracnose in northeastern Brazil. Fungal Divers. 2013, 61, 75-88. [CrossRef]

40. Murray, M.G. Rapid isolation of high molecular weight plant DNA. Nucleic Acids Res. 1980, 8, 4321-4326. [CrossRef]

41. Turner, D.; Kovacs, W.; Kuhls, K.; Lieckfeldt, E.; Peter, B.; Arisan-Atac, I.; Strauss, J.; Samuels, G.J.; Börner, T.; Kubicek, C.P. Biogeography and phenotypic variation in Trichoderma sect. Longibrachiatum and associated Hypocrea species. Mycol. Res. 1997, 101, 449-459.

42. Gardes, M.; Bruns, T.D. ITS primers with enhanced specificity for basidiomycetes - application to the identification of mycorrhizae and rusts. Mol. Ecol. 1993, 2, 113-118. [CrossRef]

43. White, T.J.; Bruns, T.; Lee, S.; Taylor, J. Amplification and direct sequencing of fungal ribosomal RNA genes for phylogenetics. PCR protocols: A guide to methods and applications. Academic Press. 1990, 315-322.

44. Carbone, I.; Kohn, L.M. A method for designing primer sets for speciation studies in filamentous ascomycetes. Mycologia 1999, 91, 553-556. [CrossRef]

45. Templeton, A.R.; Crandall, K.A.; Sing, C.F. A cladistic analysis of phenotypic associations with haplotypes inferred from restriction endonuclease mapping and DNA sequence data. III. Cladogram estimation. Genetics 1992, 132, 619-633. [CrossRef] [PubMed]

46. Thompson, J.D.; Gibson, T.J.; Plewniak, F.; Jeanmougin, F.; Higgins, D.G. The CLUSTAL_X windows interface: Flexible strategies for multiple sequence alignment aided by quality analysis tools. Nucleic Acids Res. 1997, 24, 4876-4882. [CrossRef] [PubMed] 
47. Hall, T.A. BioEdit: A user-friendly biological sequence alignment editor and analysis program for windows 95/98/NT. Nucl. Acids Symp. Ser. 1999, 41, 95-98.

48. Sudhir, K.; Glen, S.; Koichiro, T. MEGA7: Molecular evolutionary genetics analysis version 7.0 for bigger datasets. Mol. Biol. Evol. 2016, 7, 1870.

49. Huelsenbeck, J.P. MrBayes 3.2: Efficient Bayesian phylogenetic inference and model choice across a large model space. Syst. Biol. 2012, 61, 539-542.

50. Nylander, J.A.A.; Fredrik, R.; Huelsenbeck, J.P.; Joséluis, N.A. Bayesian phylogenetic analysis of combined data. Syst. Biol. 2004, 53, 47-67. [CrossRef]

51. Montri, P.; Taylor, P.W.J.; Mongkolporn, O. Pathotypes of Colletotrichum capsici, the causal agent of chili Anthracnose, in Thailand Plant Dis. 2009, 93, 17-20. [CrossRef]

52. Schoch, C.L.; Seifert, K.A.; Huhndorf, S.; Robert, V.; Schindel, D. Nuclear ribosomal internal transcribed spacer (ITS) region as a universal DNA barcode marker for Fungi. Proc. Natl. Acad. Sci. USA 2012, 109, 6241-6246. [CrossRef]

53. Xavier, K.V.; Achala, K.C.; Peres, N.A.; Deng, Z.; Vallad, G.E. Characterization of Colletotrichum species causing anthracnose of pomegranate in the southeastern U.S. Plant Dis. 2019, 103, 2771-2777. [CrossRef]

54. Tovar-Pedraza, J.M.; Mora-Aguilera, J.A.; Nava-Díaz, C.; Lima, N.B.; Michereff, S.J.; Sandoval-Islas, J.S.; Câmara, M.P.S.; Téliz-Ortiz, D.; Leyva-Mir, S.G. Distribution and pathogenicity of colletotrichum species associated with mango anthracnose in mexico. Plant Dis. 2020, 104, 137-146. [CrossRef]

55. Crouch, J.A.; Tredway, L.P.; Clarke, B.B.; Hillman, B.I. Phylogenetic and population genetic divergence correspond with habitat for the pathogen Colletotrichum cereale and allied taxa across diverse grass communities. Mol. Ecol. 2010, 18, 123-135. [CrossRef] [PubMed]

56. Shivas, R.G.; Tan, Y.P.; Edwards, J.; Dinh, Q.; Maxwell, A.; Andjic, V.; Liberato, J.R.; Anderson, C.; Beasley, D.R.; Bransgrove, K.; et al. Colletotrichum species in Australia. Australas Plant Pathol. 2016, 45, 447-464. [CrossRef]

57. Chen, L.; Fang, K.; Dong, X.F.; Yang, A.L.; Zhang, H.B. Characterization of the fungal community in the canopy air of the invasive plant Ageratina adenophora and its potential to cause plant diseases. PLoS ONE 2020, 15, e0230822. [CrossRef] [PubMed]

58. Levetin, E.; Dorsey, K. Contribution of leaf surface fungi to the air spora. Aerobiologia 2006, 22, 3-12. [CrossRef]

59. Burch, M.; Levetin, E. Effects of meteorological conditions on spore plumes. Int. J. Biometeorol. 2002, 46, 107-117. [PubMed] 